\title{
Pengaruh Jenis Pelarut Pada Distilasi Ekstraktif Pemisahan Campuran Aseton-Metanol Dengan Dinding Pemisah
}

\author{
Reynardi Risyad Raytama*, Herry Santoso, dan Yansen Hartanto
}

Program Studi Sarjana Teknik Kimia, FTI, Universitas Katolik Parahyangan

Jl. Ciumbuleuit No.94, Hegarmanah, Kec. Cidadap, Kota Bandung, Jawa Barat 40141

\section{Artikel histori :}

Diterima 03 Maret 2021 Diterima dalam revisi 10 Mei 2021 Diterima 19 Mei 2021 Online 12 Agustus 2021

\begin{abstract}
ABSTRAK: Distilasi adalah pemisahan dua campuran atau lebih ke dalam fraksi komponennya dari kemurnian yang diinginkan berdasarkan perbedaan titik didih serta volatilitas antar komponen. Pemisahan dengan metode distilasi biasa tidak efektif untuk memisahkan campuran azeotrop. Oleh karena itu, menggunakan dengan metode pressure swing distillation, azeotrope distillation, dan extractive distillation. Aseton dan metanol merupakan campuran azeotrop yang harus dipisahkan dengan pelarut. Metode yang digunakan adalah distilasi ekstraktif dengan tiga entrainer yaitu air, chlorobenzene, dan dimethyl sulfoxide (DMSO). Kolom distilasi ekstraktif konvensional dapat dimodifikasi menjadi distillation wall column (DWC) dengan menambahkan dinding pemisah untuk mengurangi konsumsi energi dan penghematan biaya. Tujuan penelitian ini adalah menentukan jenis pelarut terbaik pada setiap sistem (kolom distilasi ekstraktif konvensional dan extractive dividing wall column) dengan membandingan nilai ekonomis (biaya capital, biaya energi, dan nilai total annual cost). Penelitian dilakukan menggunakan Aspen Plus® untuk melakukan simulasi. Simulasi dengan menggunakan kolom dinding pemisah dilakukan dengan tiga kolom karena pada Aspen Plus ${ }^{\circledR}$ V8.8 tidak tersedia kolom distilasi dengan dinding pemisah. Hasil simulasi menunjukkan bahwa jenis pelarut yang terbaik untuk memisahkan campuran aseton dan methanol adalah DMSO dengan menggunakan sistem kolom distilasi ekstraktif konvensional. Biaya capital yang dihasilkan sebesar \$653.999/tahun, Biaya Energi \$3.245.929/tahun, dan Nilai TAC \$3.899.927/tahun (payback period 3 tahun).
\end{abstract}

Kata Kunci: Aseton, metanol, extractive dividing wall column

ABSTRACT: Distillation is the separation of two or more mixtures into their component fractions of the desired purity based on differences in boiling points and volatility between components. Separation by ordinary distillation method is not effective for separating azeotropic mixtures. Therefore, using the methods of pressure swing distillation, azeotrope distillation, and extractive distillation. Acetone and methanol are azeotropic mixtures that must be separated with a solvent. The method used is extractive distillation with three entrainers, namely water, chlorobenzene, and dimethyl sulfoxide (DMSO). A conventional extractive distillation column can be modified into a distillation wall column (DWC) by adding a separating wall to reduce energy consumption and save costs. The purpose of this study was to determine the best type of solvent in each system (conventional extractive distillation column and extractive dividing wall column) by comparing the economic values (capital cost, energy cost, and total annual cost). The study was conducted using Aspen Plus ${ }^{\circledR}$ to perform simulations. The simulation using a separating wall column was carried out with three columns because Aspen Plus ${ }^{\circledR}$ V8.8 there was no distillation column with a separating wall. The simulation results show that the best type of solvent to separate a mixture of acetone and methanol is DMSO using a conventional extractive distillation column system. The resulting capital cost is $\$ 653,999 /$ year, Energy Cost is $\$ 3,245,929 /$ year, and TAC Value is $\$ 3,899,927 /$ year (3 years payback period).

Keywords: Acetone, methanol, extractive dividing wall column

\section{Pendahuluan}

Dalam dunia industri, distilasi digunakan untuk proses pemisahan. Pada prosesnya, distilasi memisahkan campuran berdasarkan perbedaan titik didih setiap komponen. Sistem dengan menggunakan distilasi sederhana tidak dapat digunakan untuk memisahkan semua campuran. Di industri kimia, campuran aseton-metanol sering dijumpai untuk diolah menjadi suatu produk. aseton-

\footnotetext{
* Corresponding author

Email: reynardirisyad@gmail.com
} 
metnaol merupakan suatu campuran larutan yang membentuk titik minimum-boiling azeotrope pada sistem biner. Minimum boiling azeotrope terjadi karena penolakkan (repulsion), dimana adanya penarikkan dapat meningkatkan efektivitas tekanan uap dan menghasilkan koefisien aktivitas yang lebih tinggi dari komponen lain (S.Deshmukh \& S.V.Ashtikar, 2015).

Ada beberapa jenis pemisahan untuk memisahkan campuran azetrop ini seperti distilasi dengan perubahan tekanan (pressure swing distillation), distilasi azaeotrop, dan distilasi ekstraktif. Pada studi ini, pemisahan campuran azeotrop aseton-metnaol akan menggunakan sistem distilasi ekstraktif yang menggunakan komponen ketiga (light entrainer) sebagai pelarut dan memiliki sifat tidak menghasilkan azeotrop baru. Entrainer yang digunakan ada 3, yaitu air, chlorobenzene, dan dimethyl sulfoxide (DMSO).

Pemisahan menggunakan distilasi ekstraktif masih menghasilkan energi yang cukup besar dan menyebabkan peningkatan biaya yang cukup tinggi untuk melakukan proses pemisahannya. Dalam mengatasi hal ini akan dilakukan modifikasi pada proses distilasi tersebut dengan cara menambahkan dinding pemisah. Dengan adanya penambahan dinding pemisah ini akan mengubah bentuk kolom distilasi yang tadinya ada 2 kolom akan menjadi 1 kolom, sistem ini disebut extractive dividing wall column (EDWC).

Menurut Luyben dan Chien (2010), entrainer air adalah pelarut terbaik untuk memisahkan campuran azeotrop aseton-metanol pada distilasi ekstraktif. Penelitian ini bertujuan untuk membuktikan pengaruh jika menggunakan jenis entrainer yang berbeda terhadap pemisahan campuran azeotrop aseton-metanol apakah dengan penambahan dinding pemisah dapat menghasilkan desain kolom distilasi ekstraktif yang menghasilkan nilai total annual cost (TAC) lebih rendah daripada desain distilasi ekstraktif konvensional seiring dengan penghematan energi. Simulasi distilasi ekstraktif konvensional dan dengan penambahan dinding pemisah akan dilakukan optimasi agar menemukan titik optimum pada kedua simulasi tersebut.

\section{Metode Penelitian}

Metode penelitian akan melakukan simulasi sebanyak 6 kali untuk setiap sistem (distilasi ekstraktif konvensional dan EDWC) dengan 3 jenis entrainer yang berbeda pada software Aspen Plus ${ }^{\circledR} \quad$ V8.8 dengan menetapkan kemurnian dari aseton dan metanol 99,6\% serta entrainer 99,9\%. Kemudian akan dilakukan perhitungan nilai ekonomi untuk menentukan sistem dan jenis entrainer mana yang memiliki nilai ekonomi terendah untuk memisahkan campuran azeotrop aseton-metanol. Model termodinamika yang digunakan adalah NRTL, metode ini sesuai untuk mengaplikasikan untuk berbagai jenis campuran dan kesetimbangan cair-cair.

Secara garis besar, tahap-tahap penyelesaian melakukan simulasi penelitian ini dapat terbagi dari 5 tahap utama, yaitu:
1. Simulasi Desain dan Validasi Data Kolom Konvensional.

2. Desain awal extractive dividing wall column.

3. Optimasi dan perhitungan ekonomi kedua sistem.

4. Membandingkan nilai ekonomi kolom konvensional dengan extractive dividing wall column.

5. Menentukan jenis pelarut terbaik untuk pemisahan aseton-metanol.

\subsection{Simulasi Kolom Distilasi Ekstraktif Konvensional}

Simulasi menggunakan data awal yang digunakan berasal dari penelitian yang telah dilakukan oleh Luyben dan Chien (2010). Flowsheet untuk kolom konvensional dapat dilihat pada Gambar 1. Langkah awal simulasi adalah membuat flowsheet terlebih dahulu dengan sistem recycle kemudian dilanjutkan dengan memasukkan seluruh data dari literatur. Kemudian dilakukan penetapan distillate rate dan penyesuaian rasio refluks secara manual agar kemurnian tercapai. Data rasio refluks digunakan sebagai data tebakkan awal untuk dimasukkan pada vary. Kemudian digunakan design specification dan vary pada kedua kolom tersebut. Setelah kemurnian tercapai dilakukan optimasi guna untuk mendapatkan titik optimumnya yang menghasilkan nilai biaya capital, biaya energi, dan TAC minimum.

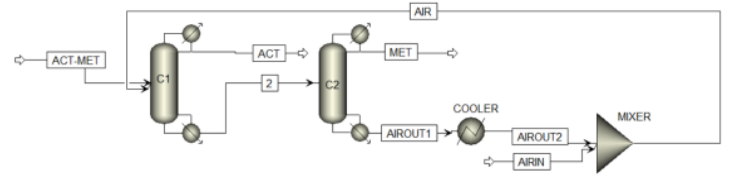

Gambar 1 Flowsheet Simulasi Kolom Konvensional

\subsection{Desain Awal Extractive Dividing Wall Column}

Desain awal yang dilakukan untuk EDWC menggunakan aturan heuristik dengan dilakukan tebakan awal yang berasal dari data kolom konvensional (DWC). Dari aturan heuristik tersebut selanjutnya dibuat konfigurasi tiga kolom RADFRAC pada Aspen Plus ${ }^{\circledR}$ yang dapat dilihat pada Gambar 2.

Persamaan yang digunakan dengan menggunakan aturan heuristik Kiss (2013) sebagai berikut:

1. $\mathrm{N}_{\mathrm{DWC}}=0,8 *\left(\mathrm{~N}_{1}+\mathrm{N}_{2}\right)$

2. Panjang sekat $=33 \%-66 \%$ dari tinggi kolom

3. Beban reboiler pada DWC $\left(\mathrm{Q}_{\mathrm{RDWC}}\right)=0,7 *\left(\mathrm{Q}_{\mathrm{R} 1}+\mathrm{Q}_{\mathrm{R} 2}\right)$

4. Beban kondensor pada DWC $\left(\mathrm{Q}_{\mathrm{CDWC}}\right)=$ $0,7 *\left(\mathrm{Q}_{\mathrm{C} 1}+\mathrm{Q}_{\mathrm{C} 2}\right)$

5. Splitter ratio sebesar 0,5

Langkah pengerjaan pada simulasi EDWC ini sama halnya seperti simulasi kolom distilasi ekstraktif konvensional. Data yang dimasukkan adalah jumlah tahap, letak umpan masuk, letak entrainer masuk, beban reboiler pada kolom bagian bawah serta data-data lainnya yang berasal dari hasil simulasi distilasi ekstraktif konvensional sebelumnya. Pada simulasi EDWC ini menggunakan design specification pada flowsheet. Beban reboiler pada kolom 3 (kolom bawah) dijadikan design specification untuk kolom 1 (kolom kiri atas) sedangkan rasio splitter untuk kolom 2 (kolom kanan atas). 


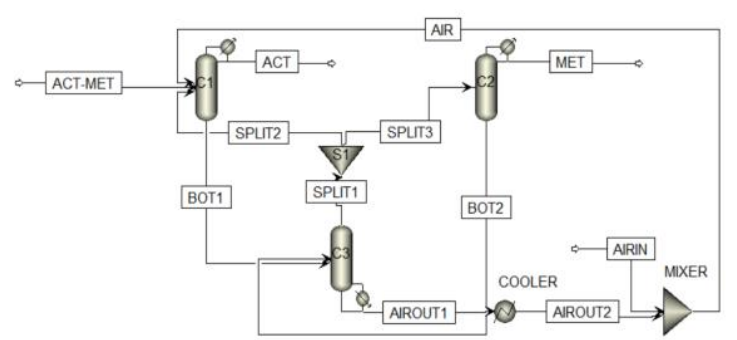

Gambar 2 Desain EDWC dengan Menggunakan Tiga Kolom RADFRAC

\subsection{Analisis Ekonomi}

Analisis ekonomi dan optimasi desain diperlukan perhitungan biaya capital, biaya energi, nilai TAC.

1. Biaya Alat

Biaya yang akan diperhitungkan pada tahap ini adalah biaya tray dan biaya kolom. Variabel yang diperlukan dalam perhitungan adalah jumlah tray total $\left(N_{T}\right)$, diameter kolom $\left(D_{c}\right)$, tinggi kolom $\left(L_{c}\right)$. Dari ketiga variabel tersebut akan memperthitungkan biaya total kolom yang terdiri dari biaya kolom dan biaya tray (Wang, 2014). Perhitungan biaya total kolom adalah sebagai berikut (Wang, 2014):

$\mathrm{Lc}=1,2 \times 0,61 \times\left(\mathrm{N}_{\mathrm{T}}-2\right)$

(1)

Biaya Kolom $=17640 \times \mathrm{Dc}^{1,066} \times \mathrm{Lc}^{0,802}$

Biaya Tray $=229 \times \mathrm{Dc}^{1,55} \mathrm{x} \mathrm{N}_{\mathrm{T}}$

Biaya Total Kolom = Biaya Kolom + Biaya Tray (4)

2. Biaya Kondensor, Reboiler, dan Cooler

Dasar dari biaya kondensor dan reboiler adalah beban kondensor dan beban reboiler itu sendiri yang akan mempengaruhi besara luas area penukar panas. Perhitungan biaya total kolom adalah sebagai berikut (Wang, 2014):

$$
\begin{aligned}
& \mathrm{A}_{\mathrm{c}}=\frac{\mathrm{Q}_{\mathrm{C}}}{\mathrm{K}_{\mathrm{C}} \times \Delta \mathrm{T}_{\mathrm{C}}} \\
& A_{R}=\frac{\mathrm{QR}_{\mathrm{R}}}{\mathrm{K}_{\mathrm{R}} \times \Delta \mathrm{T}_{\mathrm{R}}} \\
& \mathrm{A}_{\mathrm{co}}=\frac{\mathrm{QCo}_{\mathrm{Co}}}{\mathrm{K}_{\mathrm{Co}} \times \Delta \mathrm{T}_{\mathrm{Co}}} \\
& \text { Biaya } \\
& \left(7296(A C)^{0,65}+7296\left(A_{R}\right)^{0,65}+7296\left(A_{c o}\right)^{0,65}\right) \times \\
& \text { CE Index }
\end{aligned}
$$

(8)

Keterangan:
1. $\mathrm{Kc}=0.852 \mathrm{~kW} /\left(\mathrm{K} . \mathrm{m}^{2}\right)$
2. $\mathrm{K}_{\mathrm{R}}=0,568 \mathrm{~kW} /\left(\mathrm{K} \cdot \mathrm{m}^{2}\right)$
3. $\mathrm{Kco}=0,8502 \mathrm{~kW} /\left(\mathrm{K} \cdot \mathrm{m}^{2}\right)$
4. $\Delta \mathrm{T}_{\mathrm{co}}=$ Temperatur Proses Masukkan dan
Keluaran Cooler - $310 \mathrm{~K}$
5. $\Delta \mathrm{T}_{\mathrm{C}}=$ temperatur refluks drum $-310 \mathrm{~K}$
6. $\Delta \mathrm{T}_{\mathrm{R}}=$ temperatur steam (kukus) $-(\mathrm{Tr}+273)$

\section{Biaya Energi}

Biaya energi dihitung dari jumlah energi yang dibutuhkan dalam satu tahun (31.536.000 detik) dan energi didapat dari kukus. Jenis dan harga kukus dapat dilihat pada Tabel 1.

Biaya Energi $=4,7 \times 10^{-6} \times Q_{\mathrm{r}} \times \mathrm{t}$

Tabel 1 Harga Steam (YinglongWang, 2014)

\begin{tabular}{cc}
\hline Steam & Price / GJ \\
\hline LP Steam $(433 \mathrm{~K})$ & $\$ 7,72$ \\
MP Steam $(457 \mathrm{~K})$ & $\$ 8,22$ \\
HP Steam $(537 \mathrm{~K})$ & $\$ 9,88$ \\
\hline
\end{tabular}

Penelitian ini menggunakan payback period selama 3 tahun. Maka nilai total annual cost (TAC) dapat dihitung dengan persamaan berikut:

$$
\operatorname{TAC}\left(\frac{\$}{\text { tahun }}\right)=\frac{\text { Biaya Capital }(\$)}{\text { PBP }}+\text { Biaya Energi (\$) (10) }
$$

\section{Hasil dan Pembahasan}

Penelitian ini menggunakan data literatur sebagai data tebakan awal, kemudian data tersebut diatur hingga mencapai kemurnian produk sebesar 99,6\%. Perhitungan ekonomi dilakukan seragam dengan menggunakan seluruh data akhir dari Aspen Plus® baik sebelum dilakukan optimasi maupun sudah.

Data sebelum optimasi adalah data dari literatur (jumlah tahap, letak masuk umpan, letak masuk entrainer, dan rasio refluks) yang kemudian dihitung seluruh nilai ekonominya. Metode optimasi yang digunakan adalah metode sequential.

\subsection{Simulasi Kolom Distilasi Ekstraktif Konvensional}

Adapun hasil simulasi dan perhitungan nilai TAC setelah optimasi dapat dilihat pada Tabel 3 dan Gambar 3 dibawah ini.

Tabel 3 Hasil Optimasi Simulasi Kolom Konvensional

\begin{tabular}{lccc}
\hline \multicolumn{1}{c}{ Parameter } & Air & Chlorobenzene & DMSO \\
\hline Jumlah Tahap Kolom 1 (Tahap) & 64 & 47 & 38 \\
Jumlah Tahap Kolom 2 (Tahap) & 27 & 31 & 11 \\
Letak Masuk Umpan Kolom 1 (Tahap ke-) & 55 & 41 & 21 \\
Letak Masuk Umpan Kolom 2 (Tahap ke-) & 18 & 11 & 5 \\
Letak Masuk Entrainer (Tahap ke-) & 42 & 24 & 3 \\
Rasio Refluks Kolom 1 & 5,5 & 1,5 & 0,842 \\
Rasio Refluks Kolom 2 & 1,35 & 3,2 & 2,12 \\
\hline
\end{tabular}

Pada Gambar 3 menjelaskan bahwa DMSO adalah pelarut terbaik untuk memisahkan campuran asetonmetanol jika menggunakan kolom distilasi ekstraktif konvensional. Jika menggunakan DMSO, biaya energi yang dihasilkan hanya sebesar \$3.245.929/tahun dan besar biaya capital yang dihasilkan sebesar \$653.999/tahun. 


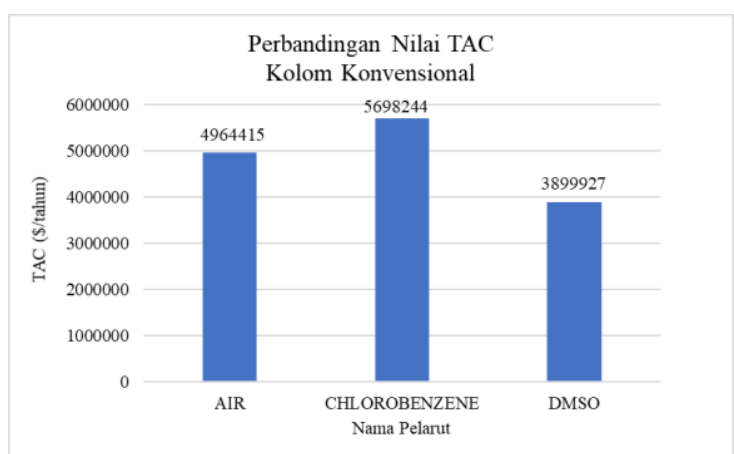

Gambar 3 Grafik Perbandingan Nilai TAC Pada Sistem Kolom Distilasi Ekstraktif Konvensional

\subsection{Simulasi Extractive Dividing Wall Column}

Adapun hasil simulasi dan perhitungan nilai TAC setelah optimasi dapat dilihat pada Tabel 4 dan Gambar 4 dibawah ini.

Tabel 4 Hasil Optimasi Simulasi EDWC

\begin{tabular}{lccc}
\hline \multicolumn{1}{c}{ Parameter } & Air & Chlorobenzene & DMSO \\
\hline Jumlah Tahap Kolom 1 (Tahap) & 54 & 66 & 65 \\
Panjang Sekat (Tahap) & 46 & 58 & 61 \\
Letak Masuk Umpan (Tahap ke-) & 40 & 48 & 45 \\
Letak Masuk Entrainer (Tahap ke-) & 26 & 32 & 27 \\
Beban Reboiler (MW) & 22 & 16 & 17 \\
Rasio Splitter & 0,2023 & 0,2205 & 0,4952 \\
\hline
\end{tabular}

Pada Gambar 4 menjelaskan bahwa DMSO adalah pelarut terbaik untuk memisahkan campuran asetonmetanol jika menggunakan sistem EDWC.

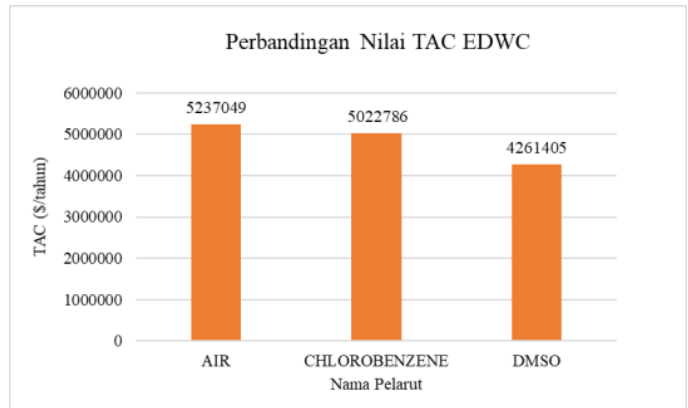

Gambar 4 Grafik Perbandingan Nilai TAC Pada Sistem EDWC

Jika menggunakan DMSO, biaya energi yang dihasilkan hanya sebesar \$3.483.276/tahun dan besar biaya capital yang dihasilkan sebesar \$778.128/tahun.

\subsection{Perbandingan Nilai TAC}

Pada Gambar 5 nilai TAC yang turun jika menambahkan dinding pemisah adalah pemisahan dengan menggunakan entrainer chlorobenzene dengan penghematan sebesar $11,85 \%$. Sedangkan untuk sistem dengan entrainer air dan DMSO dapat menambah nilai TAC secara berturut-turut sebesar 5,49\% dan 9,27\%.

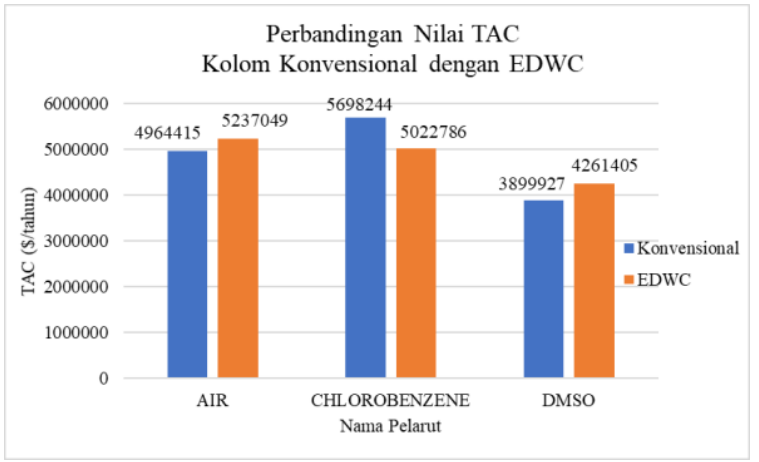

Gambar 5 Grafik Perbandingan Nilai TAC

Penambahan dinding pemisah pada sistem distilasi ektraktif konvensional jika menggunakan entrainer DMSO sangat tidak menguntungkan karena dapat meningkatkan biaya paling besar sebesar 9,27\%. Pemisahan dengan entrainer chlorobenzene menggunakan LP steam yang dimana tidak akan banyak membutuhkan energi dibandingkan jika sistem yang digunakan dengan MP steam maupun HP steam.

\subsection{Sistem Terbaik untuk Memisahkan Campuran Aseton-Metanol}

Setelah dilakukan perhitungan ekonomi, akan ditentunkan jenis entrainer terbaik untuk memisahkan campuran aseton-metanol. Dari perhitungan nilai TAC pada Gambar 5, bahwa entrainer terbaik untuk memisahkan campuran aseton-metanol adalah DMSO pada sistem kolom distilasi ekstraktif konvensional dengan harga TAC sebesar \$ 3.899.927.

\section{Kesimpulan}

Setelah dilakukan penelitian, dapat diambil kesimpulan bahwa penambahan dinding pemisah pada kolom distilasi ekstraktif konvensional lebih menguntungkan jika menggunakan entrainer chlorobenzene untuk memisahkan campuran azeotrop aseton-metanol, karena dapat menghemat nilai TAC sebesar 11,85\%. Namun, untuk setiap sistemnya penggunaan entrainer DMSO lebih menguntungkan karena memiliki nilai TAC paling rendah pada setiap sistem.

Proses terbaik untuk memisahkan campuran azeotrop aseton-metanol adalah proses kolom distilasi ekstraktif konvensional dengan menggunakan entrainer DMSO. Maka, dapat dikatakan bahwa penggunaan sistem EDWC tidak selalu menguntungkan secara ekonomis jika dibandingkan dengan kolom distilasi ekstraktif konvensional.

\section{Ucapan Terima Kasih}

Penulis mengucapkan terima kasih kepada Program Studi Sarjana Teknik Kimia Universitas Katolik Parahyangan atas dukungan yang telah diberikan. 


\section{Daftar Pustaka}

Becker, H., Godorr, S., and Kreis, H. 2001 Partitioned distillation columns - why, when \& how. Journal of Chemical Engineering, 108, 68-74.

Christopher, J. dan Litya, N., 2018, Desain Dan Optimasi Distilasi Ekstraktif Dan Extractive Dividing Wall Column Pada Pemisahan Campuran Tetrahidrofuran-Etanol

Deorukhkar, O., Rahangdale, T., dan Mahajan. 2016 Entrainer Selection Approach for Distillation Column

Deshmukh, S. dan Ashtikar, S. V., 2015, Study of Azeotrope Breaking by Pervaporation, IJEEBS, 2.

Gomez, P. dan Gil, I., 2007, Simulation of the Tetrahydrofuran Dehyrdration Process by Extractive Distillation in Aspen Plus.

Kiss, A. A. dan Suszwalak, D. J-. P. C., 2012, Enhanced bioethanol dehydration by extractive and azeotropic distillation in dividing-wall columns, Separation and Purification Technology.

Kiss, A. A., 2013, Advance Distillation Technologies: Design, Control and Applications 1ed, John Wiley and Sons Ltd, Chicester

Luyben, W. L. dan Chien, I-L., 2010, Design and Control of Distillation Systems for Separating Azeotropes, John Wiley and Sons, Inc, New Jersey, Hoboken.

Othmer, K. (2006). Encyclopedia of Chemical Technology 4ed. New Jersey: Wiley.

Smith, R., 2005, Chemical Process Design and Integration, John Wiley and Sons Ltd, Chicester.

Theresia, 2014, Optimasi Kolom Distilasi Reaktif Ekstraktif Untuk Proses Pembuatan Methylal

YinglongWang, P. C. (2014). Extractive Distillation and Pressure-Swing Distillation for THF/Ethanol Separation. $J$ Chem Technol Biotechnol. 